\title{
Influence of handpiece maintenance sprays on resin bonding to dentin
}

This article was published in the following Dove Press journal:

Clinical, Cosmetic and Investigational Dentistry

10 March 2010

Number of times this article has been viewed

\author{
Toyotarou Sugawara' \\ Atsushi Kameyama ${ }^{2}$ \\ Akiko Haruyama ${ }^{3}$ \\ Takumi Oishi ${ }^{4}$ \\ Nobuyuki Kukidome ${ }^{2}$ \\ Yasuaki Takase ${ }^{2}$ \\ Masatake Tsunoda ${ }^{2}$ \\ 'Undergraduate Student, Tokyo Dental \\ College, Chiba, Japan; ${ }^{2}$ Division of \\ General Dentistry, Tokyo Dental \\ College Chiba Hospital, Chiba, Japan; \\ ${ }^{3}$ Department of Dental Materials \\ Science, Tokyo Dental College, Chiba, \\ Japan; ${ }^{4}$ Department of Dentistry and \\ Oral Surgery, Keio University School \\ of Medicine, Tokyo, Japan
}

Correspondence: Atsushi Kameyama Division of General Dentistry, Tokyo Dental College Chiba Hospital, I-2-2, Masago, Mihama-ku, Chiba 26I-8502, Japan

Tel +8I 432703958

Fax +8I 432703943

Email kameyama@tdc.ac.jp
Objective: To investigate the influence of maintenance spray on resin bonding to dentin.

Materials and methods: The crown of extracted, caries-free human molars was transversally sectioned with a model trimmer to prepare the dentin surfaces from mid-coronal sound dentin, and then uniformly abraded with \#600 silicon carbide paper. The dentin surfaces were randomly divided into three groups: oil-free spray group where maintenance cleaner for air bearing handpieces was sprayed onto the dentin surface for $1 \mathrm{~s}$ and rinsed with water spray for $30 \mathrm{~s}$; oil-containing spray group where maintenance cleaner for micro motor handpieces was sprayed onto the dentin surface for $1 \mathrm{~s}$ and rinsed with water spray for $30 \mathrm{~s}$; and control group where the surface was rinsed with water spray for $30 \mathrm{~s}$ and then air-dried. These surfaces were then bonded with Clearfil SE Bond (Kuraray Medical), and resin composite (Clearfil AP-X, Kuraray Medical) build-up crowns were incrementally constructed on the bonded surfaces. After storage for $24 \mathrm{~h}$ in $37^{\circ} \mathrm{C}$ water, the bonded teeth were sectioned into hour-glass shaped slices $(0.7-\mathrm{mm}$ thick) perpendicular to the bonded surfaces. The specimens were then subjected to microtensile bond strength ( $\mu$ TBS) testing at a crosshead speed of $1.0 \mathrm{~mm} / \mathrm{min}$. Data were analyzed with one-way ANOVA and the Tukey-Kramer test.

Results: Maintenance spray-contaminated specimens (oil-free and oil-containing spray groups) showed significantly lower $\mu$ TBS than control specimens $(P<0.05)$. However, there was no significant difference between the spray-contaminated groups $(P>0.05)$.

Conclusion: Maintenance spray significantly reduces the bond strength of Clearfil SE Bond to dentin.

Keywords: microtensile bond strength, lubricant, maintenance spray, contamination, dentin bonding

\section{Introduction}

Clinical dentistry based on the concept of 'minimal intervention ${ }^{1}$ (MI)' is dependent on the development of effective resin composite dental restorative materials. Improvements are being sought not only in the adhesive performance and positive physical properties of these materials to allow for their use in both anterior and posterior teeth, but also in their esthetics such as color variation and level of glossiness after polishing. ${ }^{2}$

In the clinical situation, however, the many factors affecting bonding performance of these composite materials are highly important to consider. Curing light source, light intensity and curing times used have all been reported to affect bond strength, ${ }^{3,4}$ owing to differences in the degree of conversion, contraction stress and physical properties of the materials selected..$^{5-7}$ In addition, the type of bur chosen might affect both the etching effect and the penetration of resin monomer since the 
roughness of the bur influences smear layer thickness. ${ }^{8}$ It has also been reported that certain environmental conditions, for example, increased temperature and humidity in the oral cavity, significantly reduces the bond strength. ${ }^{9,10}$ Contamination is also a well-known and important factor affecting bonding performance; in particular, contamination with blood, saliva or gingival crevicular fluid significantly reduces the bond strength ${ }^{11-13}$ due to the inhibition of monomer diffusion, and therefore requires the application of isolation techniques, such as the use of a rubber dam, in the bonding procedure.

The routine use of maintenance spray for prolonging the superior performance of dental cutting handpieces is also of importance when considering sources of contamination. Maintenance spray must be used before each autoclaving or chemi-claving, and recently almost all dental offices sterilize the handpieces used with patients by autoclaving or chemiclaving for infection control. Immediately after spraying, the handpiece is briefly operated for several minutes to remove excess spray; however, it has been reported that this usual practice of removing excess spray is ineffective for preventing surface contamination. ${ }^{14}$ Some studies have evaluated the influence of maintenance spray on resin bonding to enamel, and almost of those indicated that contamination of maintenance spray had little effect on bonding. ${ }^{15-19}$ On the other hand, the contamination of maintenance spray to dentin has been some reported to affect the lower bond strength. ${ }^{19}$ However, the reports have been equivocal, ${ }^{20}$ and further studies should be needed.

The purpose of this study was, therefore, to investigate the influence of contamination with two different types of maintenance sprays on the microtensile bond strength ( $\mu$ TBS) of dentin bonded with a 2-step self-etching adhesive system. The null hypothesis tested was that contamination with maintenance spray does not influence the $\mu$ TBS of the bonded dentin.

\section{Material and methods}

\section{Bonding procedures}

Schematic illustrations of specimen preparation and $\mu$ TBS testing are shown in Figure 1. Nine caries-free extracted human molars stored in $0.5 \%$ Chloramine $\mathrm{T}$ solution at $4^{\circ} \mathrm{C}$ was used for $\mu$ TBS study. The teeth were trimmed using a model trimmer (MT-7, J Morita Tokyo Mfg. Corp., Tokyo, Japan) in order to form a long, flat dentin surface at the mid-crown level. The flat dentin surface was then polished with \#600 silicon carbide paper to create a standard smear layer. These specimens were then randomly divided to one of the following three groups, with three teeth in each group:

- Oil-free spray group: Dentin surface contaminated with an oil-free maintenance spray for air bearing handpieces (Astron Cleaner, J. Morita Mfg. Corp., Tokyo, Japan) for approximately $1 \mathrm{~s}$ at a distance of 2-3 cm, rinsed with water spray for $30 \mathrm{~s}$, and then air-dried sufficiently.

- Oil-containing spray group: Dentin surface contaminated with an oil-containing maintenance spray for ball bearing handpieces (Intra Spray, J Morita Mfg. Corp.) for approximately $1 \mathrm{~s}$ at a distance of $2-3 \mathrm{~cm}$, rinsed with water spray for $30 \mathrm{~s}$, and then air-dried sufficiently.

- Control group: Dentin surface was immediately rinsed with water spray for $30 \mathrm{~s}$ and then air-dried sufficiently.

All specimens were then treated with a self-etching priming adhesive system (Clearfil SE Bond, Kuraray Medical, Tokyo, Japan; also known as Clearfil Megabond in Japan) according to the manufacturer's instructions. The self-etching primer was applied with a three-way syringe to the surfaces for $20 \mathrm{~s}$ prior to drying. Bonding agent was then applied to the surface and polymerized by quartz-tungsten-halogen light curing unit for $10 \mathrm{~s}$ (New Light VL-II, GC, Tokyo, Japan).

After applying the bonding agent to each specimen, resin composite (Clearfil AP-X, shade A2, Kuraray Medical) was built-up incrementally (in five steps) to a height of $5 \mathrm{~mm}$. Each increment was light-cured for $20 \mathrm{~s}$ (New Light VL-II), and the specimens were then stored in distilled water for $24 \mathrm{~h}$ at $37^{\circ} \mathrm{C}$.

\section{Microtensile bond strength testing}

After storage, each bonded specimen was sectioned into four or five slabs, approximately $0.7-\mathrm{mm}$ thick, perpendicular to the bonded surface using a low-speed diamond saw (Isomet, Buehler, Lake Bluff, IL, USA) under water cooling. The slabs were trimmed using a superfine-grit diamond bur (SF \#114, Shofu, Kyoto, Japan) to an hourglass shape to form a gentle curve along the adhesive interface from both sides, as described by Sano et al. ${ }^{21}$ The width at the narrowest portion was approximately $1.4 \mathrm{~mm}$, and the thickness of the bonded area of each specimen was verified by a digital micrometer (Mitutoyo, Tokyo, Japan). The specimens were then attached to a Bencor Multi-T testing apparatus (Danville Engineering Co, San Ramen, CA, USA) with cyanoacrylate adhesive (Model Repair II Blue, Dentsply-Sankin, Ohtawara, Japan) connected to a universal testing machine (Tensilon RTC-1150-TSD, Orientec, Tokyo, Japan).

The specimens were then subjected to $\mu$ TBS testing at a crosshead speed of $1 \mathrm{~mm} / \mathrm{min}$ until failure occurred. The tensile 
a

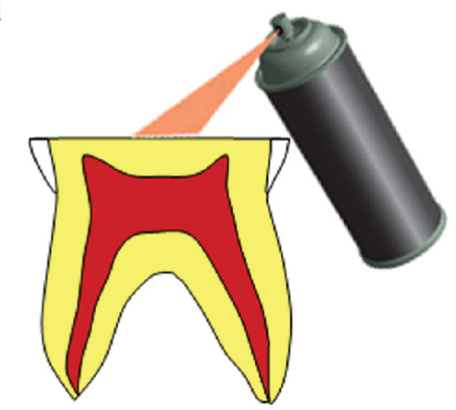

d

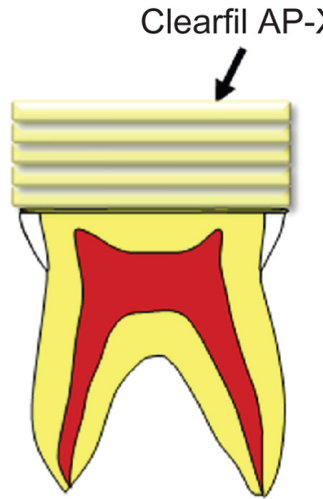

b

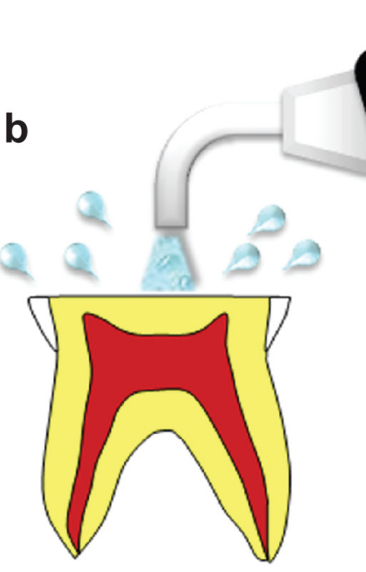

e

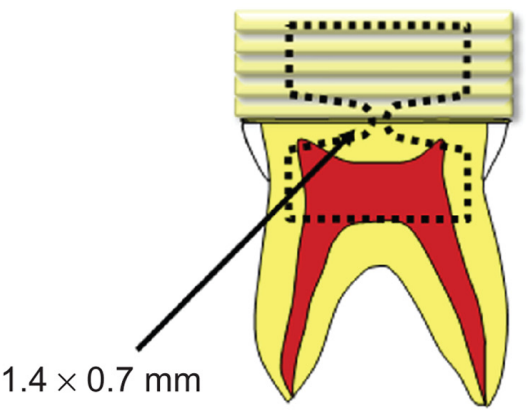

C

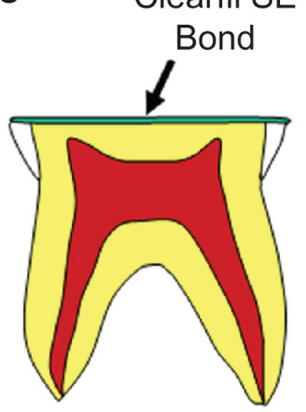

$\mathbf{f}$

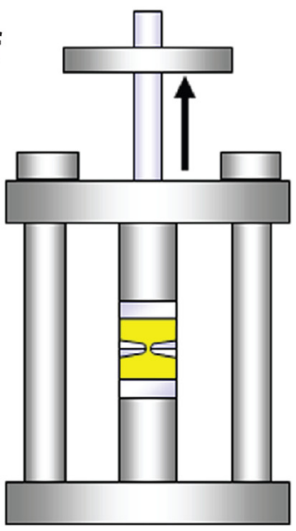

CHS: $1 \mathrm{~mm} / \mathrm{min}$

Figure I Schematic illustration of the procedure for testing microtensile bond strength ( $\mu$ TBS) of bonded dentin. Abbreviation: $\mathrm{CHS}$, crosshead speed.

bond strength was calculated as the load at failure $(\mathrm{N})$ divided by the bonded area $\left(\mathrm{mm}^{2}\right)$. Bond strength data were analyzed by one-way ANOVA and the Tukey-Kramer test. Statistical significance was set at $P<0.05$. Statistical analysis was performed using a commercially available statistical package (StatView 5.0J, SAS Institute, Cary, NC, USA).

\section{Failure mode analysis}

To determine the mode of failure, both the dentin and composite halves of all fractured specimens were visually inspected under a light microscope (MS-803, Moritex, Tokyo, Japan) at $210 \times$ magnification and further observed using a field-emission scanning electron microscope (FE-SEM; JSM-6340F, JEOL, Tokyo, Japan) at $15 \mathrm{kV}$, under the magnifications of $75 \times$ to classify the failure mode of each specimen, and $1000 \times$ to observe the details of peculiar images. Failure modes were classified as cohesive failure of resin, failure of the adhesive interface (fracture between the dentin or the hybrid layer and the overlying adhesive in the same sample), mixed resin and adhesive (R\&A) failure (interfacial and partial cohesive failure of the adhesive only or cohesive failure in the same sample), mixed that included the dentin (failure within the dentin only or mixed failure that included the dentin) or cohesive failure of dentin, wherever relevant.

\section{FE-SEM observation of resin-dentin interface}

Three human molars were used. Bonded samples prepared by same procedure as for $\mu \mathrm{TBS}$ testing were ground with increasingly finer silicon carbide paper and highly polished with a slurry solution of aluminum polishing suspension (Refine Tec, Co., Yokohama, Japan) $(1 \mu \mathrm{m}, 0.3 \mu \mathrm{m}, 0.05 \mu \mathrm{m})$. The samples were then subjected to $32 \%$ phosphoric acid (Uni-etch, Bisco, Schaumburg, IL, USA) treatment for $30 \mathrm{~s}$ and rinsed with tap water for $30 \mathrm{~s}$. The specimens were further treated with $1 \%$ sodium hypochlorite solution (Wako Pure Chemical, Osaka, Japan) for $10 \mathrm{~min}$. All specimens were subsequently dehydrated in ascending grades of ethanol $(50 \%, 70 \%, 80 \%, 90 \%, 95 \%, 99 \%$, and $99.9 \%)$ for $10 \mathrm{~min}$ each, and were further desiccated in a box with silica gel for $24 \mathrm{~h}$. The dried specimens were placed on an aluminum stub and sputter-coated with Au-Pd using a Cool Sputter Coater 
Table I Mean (SD) $\mu$ TBS (MPa), number of specimens ( $\mathrm{n}$ ) and statistical results for all tested groups

\begin{tabular}{llll}
\hline & Mean (SD) & $\mathbf{n}$ & Statistics* \\
\hline Oil-free & $29.9(12.0)$ & 14 & $\mathrm{a}$ \\
Oil-containing & $26.7(12.0)$ & 15 & $\mathrm{a}$ \\
Control & $42.9(18.9)$ & 15 & $\mathrm{~b}$ \\
\hline
\end{tabular}

Notes: *Same letters represent no statistically significant difference (Tukey-Kramer Test; $P<0.05$ ).

Abbreviation: SD, standard deviations.

(SC500A, VG Microtech, East Sussex, UK). The coated specimens were examined using the FE-SEM at $15 \mathrm{kV}$, under the magnification of $4000 \times$.

\section{Results}

Mean and standard deviation (SD) $\mu \mathrm{TBS}$ for the specimens of all three tested groups are summarized in Table 1. The non-sprayed control showed significantly higher $\mu$ TBS than the two sprayed groups $(P<0.05)$. There was no significant difference between the two sprayed groups (oil-free spray $(\mathrm{n}=14)$ and oil-containing spray $(\mathrm{n}=15)$ ) $(P>0.05)$.

Representative FE-SEM micrographs of fractured specimens after the $\mu$ TBS testing are shown in Figures $2 \mathrm{a}, 3 \mathrm{a}$ and $4 \mathrm{a}$, and distribution of the failure mode is summarized in Figure 5. Most commonly, a mixture of cohesive failure of the resin and failure of the adhesive interface/hybrid layer (R\&A failure) was observed in each group. Failure in the adhesive interface was observed only in the two sprayed groups and not in the control group. The percentage of mixed failure that included the dentin was higher in the control group than in the two sprayed groups.

FE-SEM micrographs of the cross-sectioned resin-dentin interfaces in each group are shown in Figures $2 b, 3 b$ and $4 b$. Resin tags were evident in all three groups, with no significant difference among the groups.

\section{Discussion}

The purpose of this study was to investigate the influence of contamination with two different types of maintenance sprays on the microtensile bond strength ( $\mu$ TBS) of dentin bonded with a 2-step self-etching adhesive system, Clearfil SE Bond.

Some of the previous studies applied the combined spray of lubricant and water running through the handpiece ${ }^{20}$ in order to simulate the clinical situation. It has been reported that the spray contents was discharged up to at least $240 \mathrm{~min}$, but the amount of discharge was gradually reduced..$^{14}$ Their results suggested that uniform discharging of spray contents into entire the dentin surface might be difficult. In this study, therefore, the spray was applied directly in order to contaminate the dentin surface, referred to Rosa et al and Matos et al. ${ }^{18,19}$

Powers et $\mathrm{a}{ }^{15}$ and Knight et $\mathrm{al}{ }^{17}$ evaluated the handpiece lubrication on bond strength of enamel using two multi-step etch and rinse adhesive systems (All-Bond 2, Bisco; Optibond FL, Kerr; and Gluma 2000, Heraeus Kulzer), and they found that the significant difference between the mean bond strengths for the group prepared with a sterilized unlubricated handpiece and the group prepared with a lubricated handpiece. However, other studies which evaluate the bond
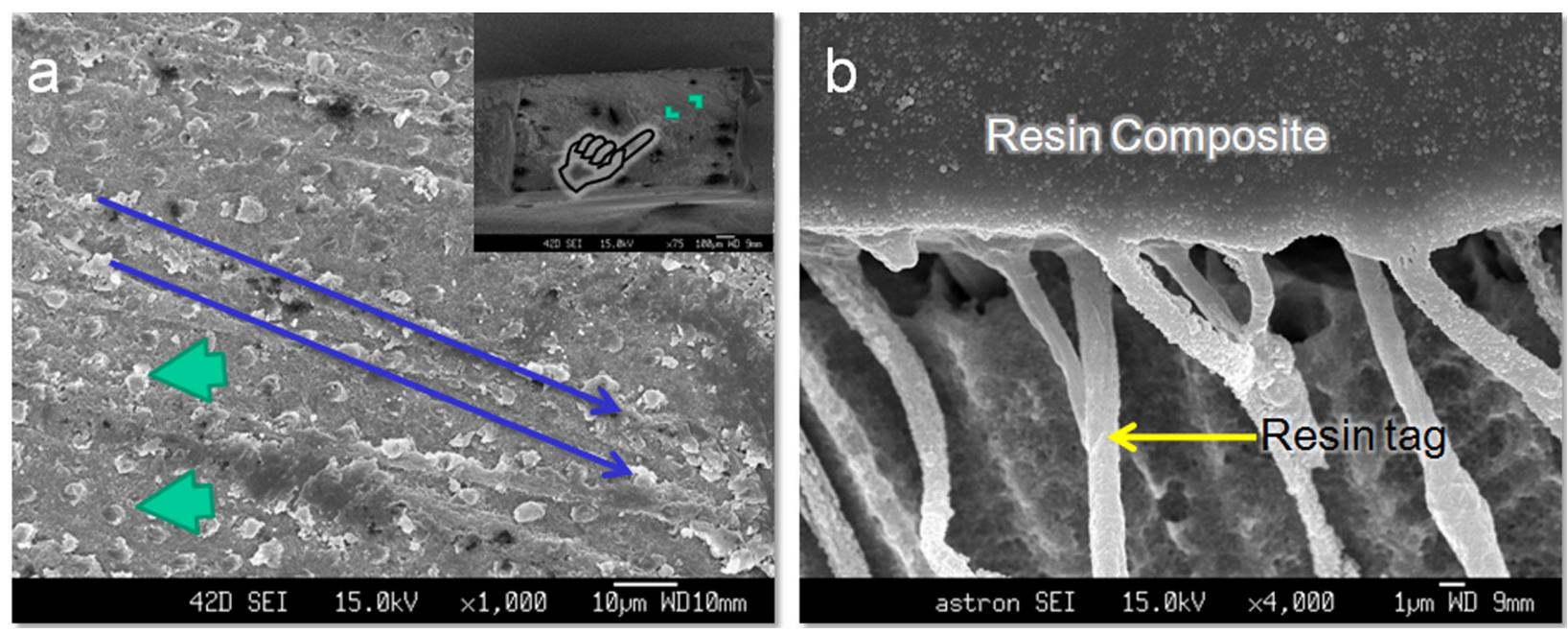

Figure 2 FE-SEM micrographs of oil-free maintenance spray (Astron Cleaner) group. a) High magnification view of the failed dentin-side surface (the area indicated with the pointer in the inset). Almost all dentin tubules are plugged with resin component (green arrows), and some scratches resulting from preparation with $\mathrm{SiC}$ paper are evident (blue arrows). b) Cross-section view of the resin-dentin interface. Numerous resin tags are visible (yellow arrow). 

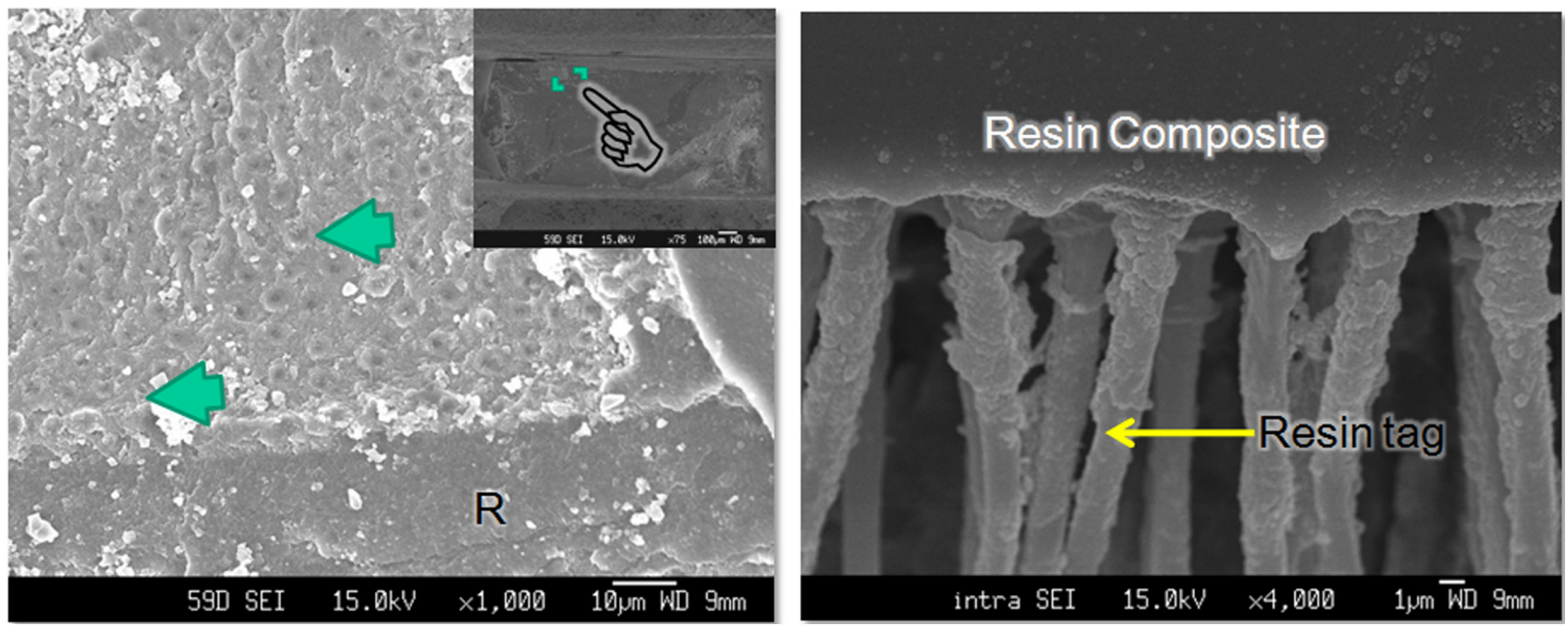

Figure 3 FE-SEM micrographs of oil-containing maintenance spray (Intra Spray) group. a) High magnification view of the failed dentin-side surface (the area indicated with the pointer in the inset). In this specimen, the cohesive failure in the resin was observed in almost all areas (R), while resin-plugged dentin tubules were partially observed (green arrows). b) Cross-section view of the resin-dentin interface. Numerous resin tags (yellow arrow) were seen, similarly to the other groups.

strengths of oil-contaminated enamel with multi-step etch and rinse adhesives stated that contamination had little effect on bond strength. ${ }^{15,18}$ Rosa et al assumed that etch and rinse adhesive had little effect of oil contamination, because the etchant was efficient in removing much of the oil. ${ }^{18}$

It has also been some reported about the influence of handpiece lubrication on bond strength, but the results have been equivocal. . $^{15,16,19,20}$ Roberts et al investigated using a 2-step etch and rinse adhesive (Single Bond, 3M ESPE), a 2-step self-etch adhesive (Clearfil SE Bond), and a 1-step self-etch adhesive (One-up Bond F, Tokuyama Dental), and resulted that there were no significant differences in dentin bond strength between the non-contaminated control and the spray-contaminated groups regardless of the type of handpiece or use of routine lubrication in each adhesive system. ${ }^{20}$ On the other hand, Matos et a ${ }^{19}$ reported that the bond strength of Clearfil Protect Bond (Kuraray Medical), a 2-step self-etching adhesive system which improved on Clearfil SE Bond ${ }^{22}$ to dentin was lower more than half compared with a non-contaminated group. Our study also revealed that contamination of maintenance spray significantly affected to reduce the $\mu$ TBS of bonded dentin. Differ to etch and rinse adhesive, it is not needed the water spraying before applying self-etch adhesive. Therefore, the adverse
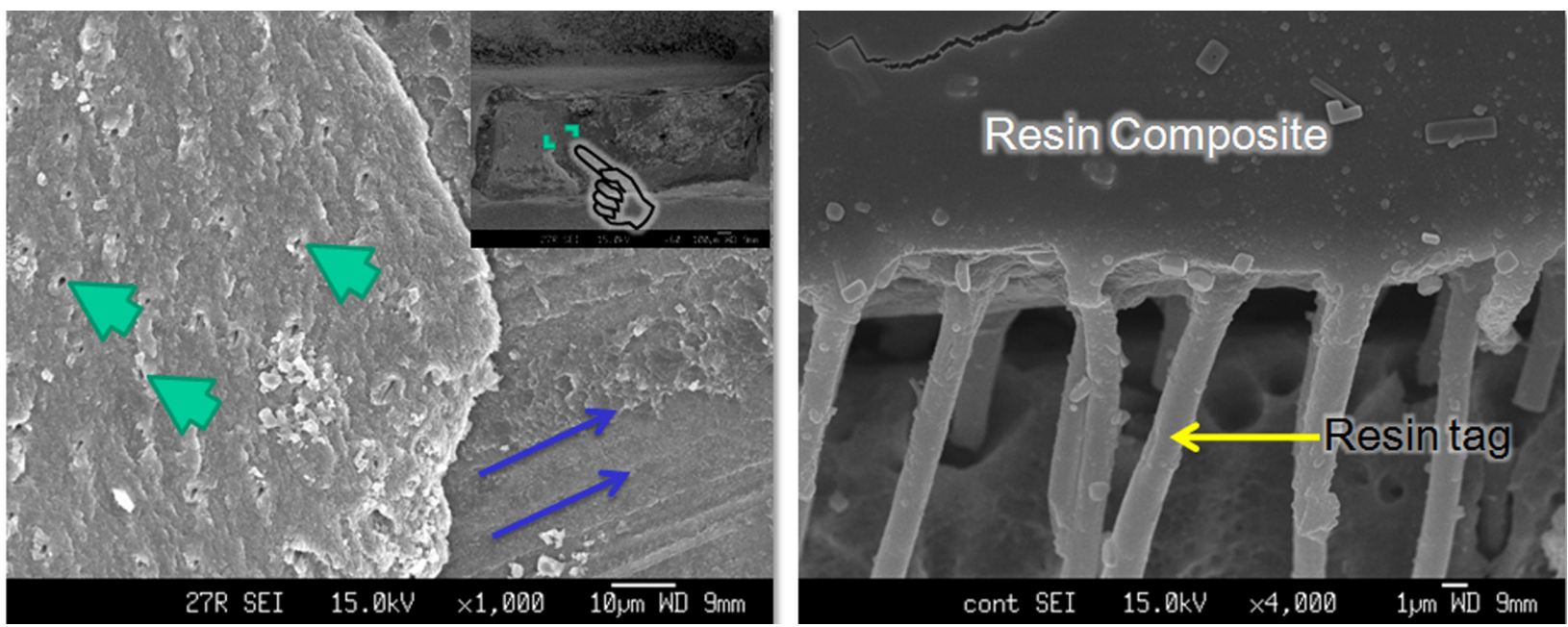

Figure 4 FE-SEM micrographs of control (non-sprayed) group. a) High magnification view of the failed dentin-side surface (the area indicated with the pointer in the inset). The composite side shows dentin tubules (green arrows). Scratches caused by preparation with SiC paper are apparent (blue arrows). b) Cross-section view of resin-dentin interface. Numerous resin tags (yellow arrow) are apparent, similarly to the other groups. 


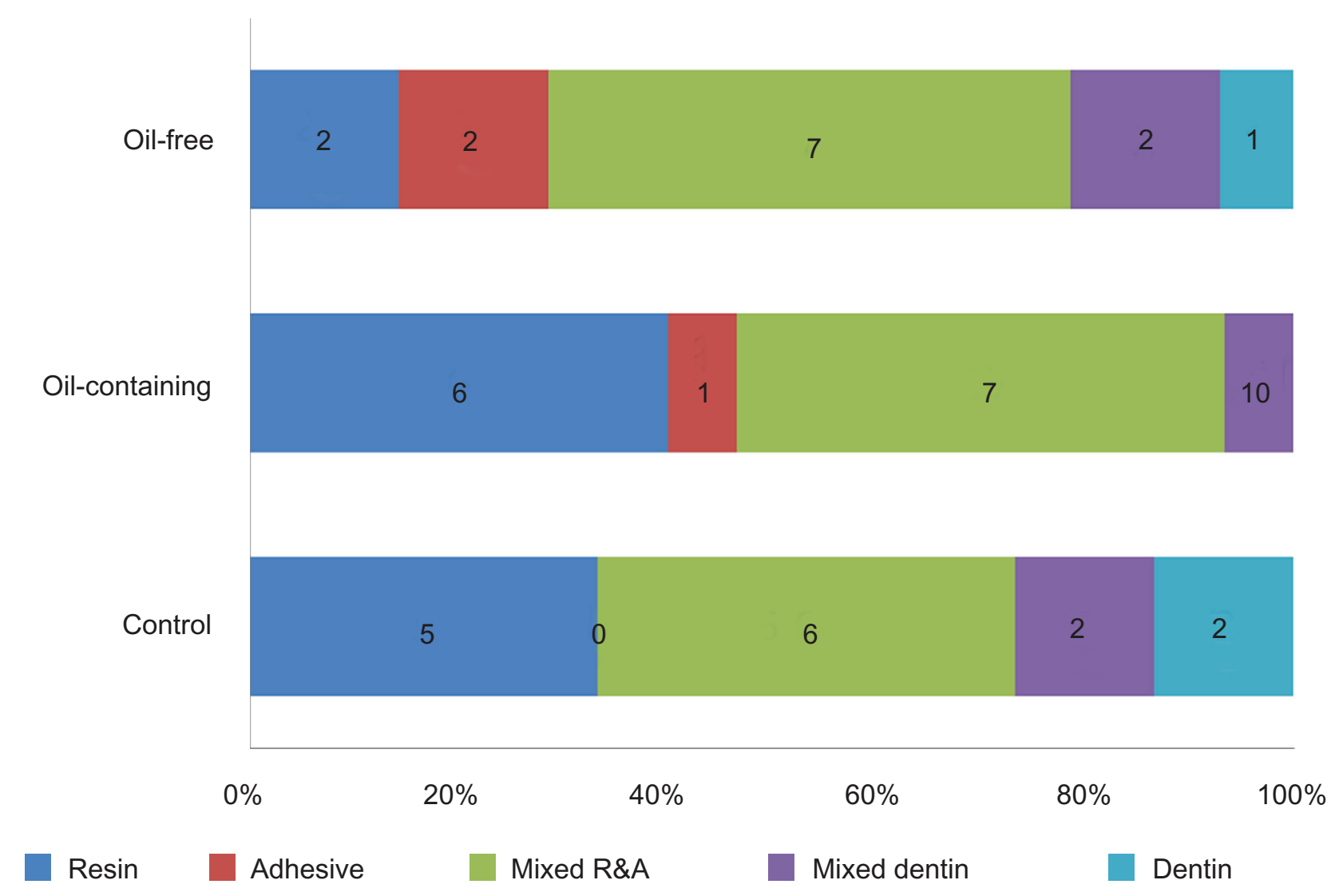

Figure 5 Percentage distribution of failure modes.

effect of maintenance spray on self-etch adhesive might be larger than that on etch and rinse adhesive. In the results of this study, we suggested that the null hypothesis tested in this study that contamination with maintenance sprays does not influence the $\mu$ TBS of dentin bonded with 2-step self-etch adhesive can be rejected.

This study also compared two different types of maintenance sprays - oil-free spray (Astron Cleaner) and oilcontaining spray (Intra Spray), but no significant difference was found between the sprays. Intra Spray contains isoparaffin oil for lubrication, and Astron Cleaner contains ethanol but do not contain any type of oil. In FE-SEM micrographs of the fractured surface, the failure within the hybridized dentin area was mainly observed in the oilcontaining spray group, and failure at the adhesive interface was rarely observed. Furthermore, the long thick resin tags visible on the FE-SEM micrographs of the cross-sectioned resin-dentin interface were the same as those observed in the other groups. These results indicated that the lower $\mu$ TBS in the oil-containing spray group might not be due to the inhibition of resin penetration. Since both spray cans contain liquefied petroleum gas as an aerosol propellant, this might be attributable to decrease in the mechanical properties of the adhesive interfacial area. Further studies are needed to clarify what component was affected on resin bonding.

In order to perform ideal bonding, it should be eliminated the all inhibitors on resin bonding in the clinical situation. As already mentioned, contamination of blood or saliva significantly reduces the bond strength ${ }^{12,13}$ due to the inhibition of resin penetration. In order to prevent cavity surfaces produced by such contaminants, dentists typically use the rubber dam isolation technique, which is useful for creating a suitable environment for resin bonding since it not only isolates the surface from these fluids, but also reduces intraoral humidity. However, the technique is not able to prevent contamination from handpiece maintenance spray since the spray has been reported to discharge for at least 240 minutes; ${ }^{23}$ thus, the usual practice of removing excess spray by operating the handpiece for just a few minutes is ineffective in preventing the contamination. ${ }^{14}$ Future work should focus on eliminating the contaminants from maintenance sprays in order to improve bonding performance to dentin. 


\section{Conclusion}

Within the limitations of this study, the following conclusions are drawn:

Contamination from maintenance spray significantly affects the microtensile bond strength to dentin. However, there is no difference between the effects of oil-free and oil-containing maintenance sprays on the reduction in the microtensile bond strength to dentin.

\section{Acknowledgments/disclosures}

We would like to thank Mr Katsumi Tadokoro (Oral Health Science Center, Tokyo Dental College) for technical advice on using the SEM. The author reports no conflicts of interest in this work.

\section{References}

1. Tyas MJ, Anusavice KJ, Frencken JE, Mount GJ. Minimal intervention dentistry - a review: FDI Commission Project 1-97. Int Dent J. 2000; 50:1-9.

2. Van Landuyt KL, Snauwaert J, De Munck J, et al. Systematic review of the chemical composition of contemporary dental adhesives. Biomaterials. 2007;28:3757-3785.

3. Amaral CM, Peris AR, Ambrosano GM, Swift EJ Jr, Pimenta LA. The effect of light-curing source and mode on microtensile bond strength to bovine dentin. J Adhes Dent. 2006;8:41-45.

4. Shinkai K, Suzuki S, Katoh Y. Effect of light intensity for adhesive on shear bond strength to dentin. Dent Mater J. 2008;27:660-665.

5. Soares LE, Liporoni PC, Martin AA. The effect of soft-start polymerization by second generation LEDs on the degree of conversion of resin composite. Oper Dent. 2007;32:160-165.

6. Feilzer AJ, Dooren LH, De Gee AJ, Davidson CL. Influence of light intensity on polymerization shrinkage and integrity of restoration-cavity influence. Eur J Oral Sci. 1995;103:322-326.

7. Kameyama A, Kato J, Yoshinari M, Kotoku Y, Akashi G, Hirai Y. Ultimate micro-tensile strength of dental adhesives cured at different light source. J Photopolym Sci Technol. 2008;21:31-35.

8. Kameyama A, Oishi T, Sugawara T, Hirai Y. Microtensile bond strength of indirect resin composite to resin-coated dentin: Interaction between diamond bur roughness and coating material. Bull Tokyo Dent Coll. 2009;50:13-22.
9. Besnault $\mathrm{C}$, Attal J. Influence of a simulated oral environment on dentin bond strength of two adhesive systems. Am J Dent. 2001;14:367-372.

10. Chiba Y, Miyazaki M, Rikuta A, Moore BK. Influence of environmental conditions on dentin bond strengths of one-application adhesive systems. Oper Dent. 2004;29:554-559.

11. Abdalla AI, Davidson CL. Bonding efficiency and interfacial morphology of one-bottle adhesives to contaminated dentin surfaces. Am J Dent. 1998;11:281-285.

12. Yoo HM, Pereira PNR. Effect of blood contamination with 1-step selfetching adhesives on microtensile bond strength to dentin. Oper Dent. 2006;31:660-665

13. Fritz UB, Finger WJ, Stean H. Salivary contamination during bonding procedures with a one-bottle adhesive system. Quintessence Int. 1998;29:567-572.

14. Pong ASM, Dyson JE, Darvell BW. Discharge of lubricant from air turbine handpieces. Brit Dent J. 2005;198:637-640.

15. Xie J, Powers JM, McGuckin RS. In vitro bond strength of two adhesives to enamel and dentin under normal and contaminated conditions. Dent Mater. 1993;9:295-299.

16. Powers JM, Finger WJ, Xie J. Bonding of composite resin to contaminated human enamel and dentin. J Prosthodont. 1995;4:28-32.

17. Knight JS, Draughn R, Evans MD. Effects of handpiece lubricant on resin-based composite bond strength to enamel. Am J Dent. 1999; $12: 116-118$

18. Rosa BT, Heymann HO, Swift Jr EJ, Perdigao J, Ritter AV. Shear bond strengths of one-bottle adhesives to oil-contaminated enamel. J Esthet Dent. 2000;12:139-145.

19. Matos AB, Oliveira DC, Vieira SN, Netto NG, Powers JM. Influence of oil contamination on in vitro bond strength of bonding agents to dental substrates. Am J Dent. 2008;21:101-104.

20. Roberts HW, Vandewalle KS, Charlton DG, Leonard DL. Effect of handpiece maintenance method on bond strength. Oper Dent. 2005;30:528-532.

21. Sano H, Shono T, Sonoda H, et al. Relationship between surface area for adhesion and tensile bond strength: Evaluation of a micro-tensile bond test. Dent Mater. 1994;10:236-240.

22. Kameyama A, Tsumori M, Ushiki T, et al. Fluoride release from newly developed dental adhesives. Bull Tokyo Dent Coll. 2002;43:193-197.

23. Plasmans PJJM, Creuger NHJ, Hermsen RJ, Vrijhoef MMA. Intraoral humidity during operative procedures. J Dent. 1994;22:89-91.
Clinical, Cosmetic and Investigational Dentistry

\section{Publish your work in this journal}

Clinical, Cosmetic and Investigational Dentistry is an international, peer-reviewed, open access, online journal focusing on the latest clinical and experimental research in dentistry with specific emphasis on cosmetic interventions. Innovative developments in dental materials, techniques and devices that improve outcomes

\section{Dovepress}

and patient satisfaction and preference will be highlighted. The manuscript management system is completely online and includes a very quick and fair peer-review system, which is all easy to use. Visit http://www.dovepress.com/testimonials.php to read real quotes from published authors. 